\title{
The relationship of dielectric response and water activity in food
}

\author{
Ryan C. Renshaw ${ }^{\mathrm{a}, \mathrm{b}}$, Georgios A. Dimitrakis ${ }^{\mathrm{b}}$, John P. Robinson ${ }^{\mathrm{b}}$, Samuel W. Kingman ${ }^{\mathrm{b}}$ \\ a e2v technologies (uk ltd), 106 Waterhouse Lane, Chelmsford, Essex, UK, CM1 2QU \\ ${ }^{\mathrm{b}}$ Energy and sustainability research division, Faculty of engineering, University of Nottingham, \\ University park, Nottingham, NG7 2RD
}

Keywords: Dielectric, sorption, water activity, multilayer, monolayer, food

\begin{abstract}
This study has deduced a correlation between points of inflection of water activity and loss factor with respect to moisture content. A point of inflection in loss factor with respect to moisture content was found to coincide with the sorption isotherm point of inflection that defines the transition from multilayer to solution in every instance analysed, with an average difference of just $0.01 \mathrm{~kg} \cdot \mathrm{kg}^{-1}$. Food can support microbial growth and chemical reactions in water activity levels above this critical transition. This correlation was discovered using published dielectric and sorption data for specific foods at similar temperatures. It was found that low sugar foods containing high levels of hydrocolloids generally exhibited different behaviour from fruits. This shows that microwave heating behaviour will be different in fruits compared to low sugar foods with high hydrocolloid content when drying to achieve a certain water activity and therefore shelf life.
\end{abstract}




\section{Introduction}

Almost every food product is dried at least once at one point of its preparation (Sokhansanj \& Jayas, 2006). Drying of food typically occurs as part of the cooking process. Dehydration can also be required specifically for food preservation. The reduced weight and bulk of dehydrated products and their improved stability reduces product storage and distribution costs (Toledo, 2007). Microwave heating can be used in some food drying applications as it provides some unique benefits compared to conventional forms of heating. Unlike conventional heating, microwave heating does not rely on temperature gradients for heat transfer. Microwave heating is volumetric, instantaneous, and high power densities can be applied (Clark \& Sutton, 1996). It has been successfully employed in a number of food drying applications, such as biscuit finish drying where reduced cracking in biscuits was obtained through superior uniformity of final moisture content, and production rates were improved significantly (Bernussi, et al., 1998; Koral, 2004). Pasta drying is another microwave application were the time taken to dry pasta was reduced (Altan \& Maskan, 2005; Berteli \& Marsaioli Jr., 2005).

The drying of materials is largely governed by the isosteric heat of sorption, and by its water activity relative to that of surrounding air (Richardson, et al., 2002; Wang \& Brennan, 1991). Sorption isotherms plot the moisture dependence of water activity, and multiple sorption isotherms taken at different temperatures can be used to define the isosteric heat (Wang \& Brennan, 1991). The points of inflection observed in sorption isotherms are used to define the transition from monolayer to multilayer, and the transition from multilayer to solution (Yanniotis \& Blahovec, 2009). These two critical transitions defined by the sorption isotherm is shown in Fig. 1, where both water activity and loss factor of freeze dried potato are plotted against moisture content, as measured by Mudgett et al. (1980) (Yanniotis \& Blahovec, 2009). The first point of inflection defines the monolayer moisture content, which is a transition from monolayer 
moisture to multilayer moisture and can be calculated using the BET equation (Yanniotis \& Blahovec, 2009; Al-Muhtaseb, et al., 2002). The monolayer moisture content theoretically assumes that each hydrophilic group has a water molecule associated with it, which can occur due to dipole-dipole forces, dipole-ion interactions, van der Waals forces, or hydrogen bonding (Labuza \& Altunakar, 2007). Below the monolayer moisture content the moisture is tightly bound, with an enthalpy of vaporisation considerably higher than that of pure water (Yanniotis \& Blahovec, 2009; Wang \& Brennan, 1991). Foods that are dehydrated below the monolayer moisture content have a maximum shelf-life (Labuza \& Altunakar, 2007). Examples of foods dried below the monolayer moisture content are potato crisps, crackers and biscuits (Schmidt, 2007). The next point of inflection is the transition from multilayer to solution. Once the moisture is in solution there is enough water mobility to support microbial growth and chemical reactions (Labuza \& Altunakar, 2007). Due to its importance for drying, and for determining food stability, sorption isotherms of foods have been extensively studied, with a large number of empirical and kinematic models used to mathematically describe sorption isotherms (AlMuhtaseb, et al., 2002). 


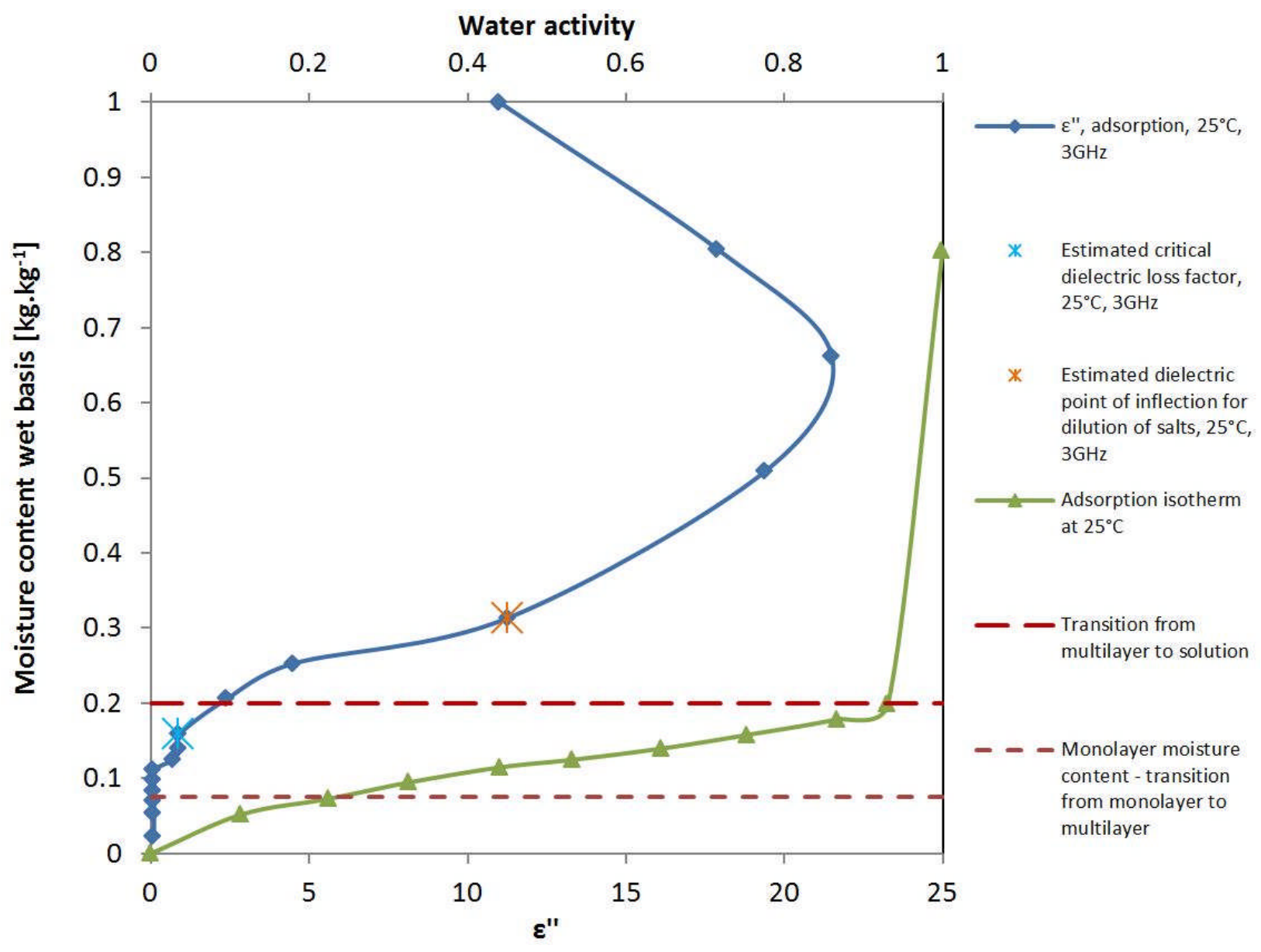

Fig. 1 - Adsorption isotherm and corresponding loss factor at $25^{\circ} \mathrm{C}$ of freeze dried potato at 3GHz taken from Mudgett et al. (1980)

The dielectric response of foods dictates their heating, and the uniformity of the heating, when subject to Radio Frequency (RF) or microwave radiation. The moisture dependence of dielectric properties is critical for drying applications. It can lead to thermal runaway problems if the material heats more readily at lower moisture contents, or it can lead to moisture levelling effects if the material heats less readily at lower moisture contents (Schiffmann, 2006; Gard, et al., 2014; Metaxas, 1996). Compared to the study of sorption isotherms, there are relatively few studies describing the moisture dependence of dielectric properties of foods, and there is no recognised standard equation used to describe the moisture dependence of dielectric properties of foods. 
The dominant mechanisms responsible for dielectric loss in foods are dipolar rotation and ionic conduction (Jiao, et al., 2015). Studies show that the loss factor does not increase much with respect to moisture content until a "critical dielectric moisture content" is reached, after which a rapid increase in loss factor with respect to moisture content can be observed as shown in Fig. 1 (Schiffmann, 2006; Metaxas \& Meredith, 1993; Mudgett, et al., 1980; Tulasidas, et al., 1995; Guo, et al., 2008). The point of inflection at which the loss factor increases rapidly with respect to moisture content can be thought of as the point at which there is a significant change in water mobility to better support dielectric loss mechanisms (Metaxas \& Meredith, 1993). The critical dielectric moisture content has been observed in foods at both RF and microwave frequencies, suggesting that mobility is important for both ionic conduction, and dipolar rotation (Sacilik \& Colak, 2010). A second point of inflection has been observed at high moisture contents in numerous foods (Mudgett, et al., 1980; Kim, et al., 1998; Feng, et al., 2002; Tulasidas, et al., 1995). This second point of inflection shows a decrease in the rate of change of loss factor with respect to moisture content as shown in Fig. 1, and it is caused by reduced ionic conduction. This reduction in ionic conduction occurs due to dilution of the salts (Mudgett, et al., 1980).

The relatively flat dielectric response below the critical dielectric moisture content shows that the dielectric response is being restricted by interaction between the water and the food. Both dipolar rotation and ionic conduction require water mobility, and both nuclear magnetic resonance spectroscopy (NMR) and water activity studies show that water mobility is limited at lower moisture contents (Schmidt, 2007). It can be concluded that water mobility is extremely important for dielectric response, and consequently for microwave drying. The reduction in water activity and loss factor with respect to moisture content between intermediate and low moisture contents suggests that both water activity and dielectric response are dependent on water mobility, and their behaviour may therefore be linked. Study of their relationship is 
therefore of interest as there could be inter-dependency. This inter-dependency could be consequently used to build dielectric relationships, and to better understand dielectric behaviour.

There are very few examples in literature where the points of inflection on sorption isotherms are compared to the critical dielectric moisture content. Dielectric property studies are typically completely separate from sorption isotherm studies, as they belong to different physics disciplines and there are no studies that investigate an overall relationship between water activity and dielectric properties. Mudgett et al. (1980) plotted the dielectric properties of potato against water activity, Holtz et al. (2010) plotted penetration depth against water activity, while MartinEsparza et al. (2006) plotted dielectric properties of apples against water activity. However, each of these works only studied one food, so no conclusions were drawn about the general relationship between dielectric and water activity behaviour in foods. The present study aims to determine if a relationship exists between the inflection points of moisture dependent dielectrics and sorption isotherms using published data.

A literature review was carried out to identify foods for which the dielectric response with respect to moisture is published, as well as the corresponding sorption isotherms. Moisture dependant dielectric response and sorption isotherm data was obtained for eight foods as shown in Table 1.

It was important to use a common type of sorption when comparing moisture dependent dielectric properties with sorption isotherms, as sorption isotherms of food commonly display hysteresis between desorption and adsorption (Al-Muhtaseb, et al., 2002). This meant that some published dielectric data could not be used in the present study, such as the dielectric properties of hard red winter wheat measured by Nelson \& Stetson (1976). This dielectric data contained 
both adsorbed and desorbed data points and could therefore not be compared to a desorption or adsorption isotherm.

The sorption isotherm measurements used in the present study were taken at exactly the same temperature as the dielectric measurement, except for wheat flour, yellow dent corn, and grapes. For yellow dent corn the dielectric measurement was taken at $24^{\circ} \mathrm{C}$ and the sorption isotherm was measured at $25^{\circ} \mathrm{C}$, while dielectric measurement was taken at $25^{\circ} \mathrm{C}$ and the sorption isotherm was measured at $30^{\circ} \mathrm{C}$ for grapes. The dielectric measurement for wheat flour was taken at $22^{\circ} \mathrm{C}$ while the sorption isotherm measurement was taken at $20^{\circ} \mathrm{C}$.

The monolayer moisture content was calculated by fitting the BET sorption isotherm model to the experimental data using non-linear regression, where BET stands for Brunauer, Emmet, and Teller, who are the authors that derived the sorption equation (Brunauer, et al., 1938). The equation is shown below were $M_{d b}$ is the moisture content dry basis, $a_{w}$ is water activity, $M_{o}$ is the monolayer moisture content which acts as a fitting parameter, and $C$ is also a fitting parameter.

$M_{d b}=\frac{M_{0} C a_{w}}{\left(1-a_{w}\right)\left[1+(C-1) a_{w}\right]}$

The non-linear regression fitting of the BET model was carried out over a water activity range of 0-0.45, as the BET model is only effective at representing sorption isotherms at lower water activity ranges (McMinn, et al., 2007). Non-linear regression fitting of the BET equation was carried out using Minitab 16 software (Minitab Inc., Pennsylvania State University, USA), which 
is a statistical analysis software package. The best fit of the non-linear regression was ascertained using residual sum of squares, which is described as follows:

$R S S=\sum\left(u_{e}-u_{p}\right)^{2}$

Where $u_{e}$ is the experimental value, and $u_{p}$ is the value predicted by the model. Non-linear regression is commonly used to curve fit the BET equation to experimental data (Wang \& Brennan, 1991; McLaughlin \& Magee, 1998; Kaymak-Ertekin \& Gedik, 2004). Regression analysis is also used in other fields to curve fit experimental data to models, and to determine the suitability of models for particular applications (Valipour, et al., 2013; Valipour, et al., 2017). Unlike the monolayer, there is no recognised mathematical method for determining the transition from multilayer to solution. This transition was determined by inspecting the sorption isotherm curve for an increase in the rate of change of water activity with respect to moisture content.

For each graphical comparison of the points of inflection, moisture content wet basis was plotted agianst water acitvity, and loss factor was added to a second X-axis. Water content was plotted as wet basis, as this is convention for the reporting of dielectric properties. The points of inflection were recorded in a comparison table for all the instances analysed.

\section{Results and discussion}

The desorption isotherm and corresponding loss factor at $3 \mathrm{GHz}$ for freeze dried potato is shown in Fig. 1. The data presented in Fig. 1 was taken from Mudgett et al. (1980), where both measurement sets were taken on a adsorption basis. Although duplicate measurements were made, standard deviations were not presented by Mudgett et al. (1980). The BET monolayer 
moisture content was calculated to be $0.076 \mathrm{~kg} \cdot \mathrm{kg}^{-1}$ wet basis. It can be seen that the loss factor does not change either before the monolayer, or for a period afterwards. There is a jump in loss factor from 0.1 to 0.9 at $0.12 \mathrm{~kg}_{\mathrm{kg}} \mathrm{kg}^{-1}$ wet basis, after which the loss factor is relatively constant until a moisture content of $0.16 \mathrm{~kg} \cdot \mathrm{kg}^{-1}$ wet basis. The first point of inflection in loss factor occurs at a moisture content of approximately $0.16 \mathrm{~kg}_{\mathrm{kg}} \mathrm{kg}^{-1}$ wet basis, which is just before the water starts behaving like a solution at $0.2 \mathrm{~kg} \cdot \mathrm{kg}^{-1}$ wet basis. When the moisture starts acting like a solution it has enough mobility to support chemical reactions and the growth of micro-organisms (Labuza $\&$ Altunakar, 2007). For the case of potatoes, Fig. 1 provides evidence that the mobility required to support micro-organism growth is similar to the mobility required for moisture dependant dielectric loss mechanisms. The low loss factor at moisture contents below the multilayersolution transition provides complications with respect to microwave heating. Low loss materials are more difficult to heat using microwave radiation (Bradshaw, et al., 1998).

After the critical dielectric moisture content, the next significant point of inflection for the loss factor occurs at approximately $0.31 \mathrm{~kg} \cdot \mathrm{kg}^{-1}$ wet basis. This point of inflection constitutes a decrease in $d \varepsilon " / d M_{w b}$, where $\varepsilon "$ is loss factor and $M_{w b}$ is moisture content wet basis. This decrease in $d \varepsilon " / d M_{w b}$ is caused by a dilution of the salts which reduces the ionic conduction component of the loss factor (Mudgett, et al., 1980). The dilution continues to negatively affect $d \varepsilon " / d M_{w b}$ until the loss factor decreases. The zero point of $d \varepsilon " / d M_{w b}$ occurs at approximately $0.60 \mathrm{~kg} \cdot \mathrm{kg}^{-1}$ wet basis, after which the loss factor decreases until saturation is reached.

Holtz et al. (2010) carried out a similar measurement to Mudgett et al. (1980) of potato at 2.8GHz as shown in Fig. 2. Single points of measurement are presented for the dielectric measurements, while the sorption isotherm points represent the average measurement of four separate samples. The standard deviation of the sorption isotherm measurements were not 
presented by Holtz et al. (2010) in tabular format, please see the study by Holtz et al. (2010) for sorption isotherm error bars. The BET monolayer was calculated to be $0.050 \mathrm{~kg}^{\mathrm{k}} \mathrm{kg}^{-1}$ wet basis using the data presented by Holtz et al. (2010).

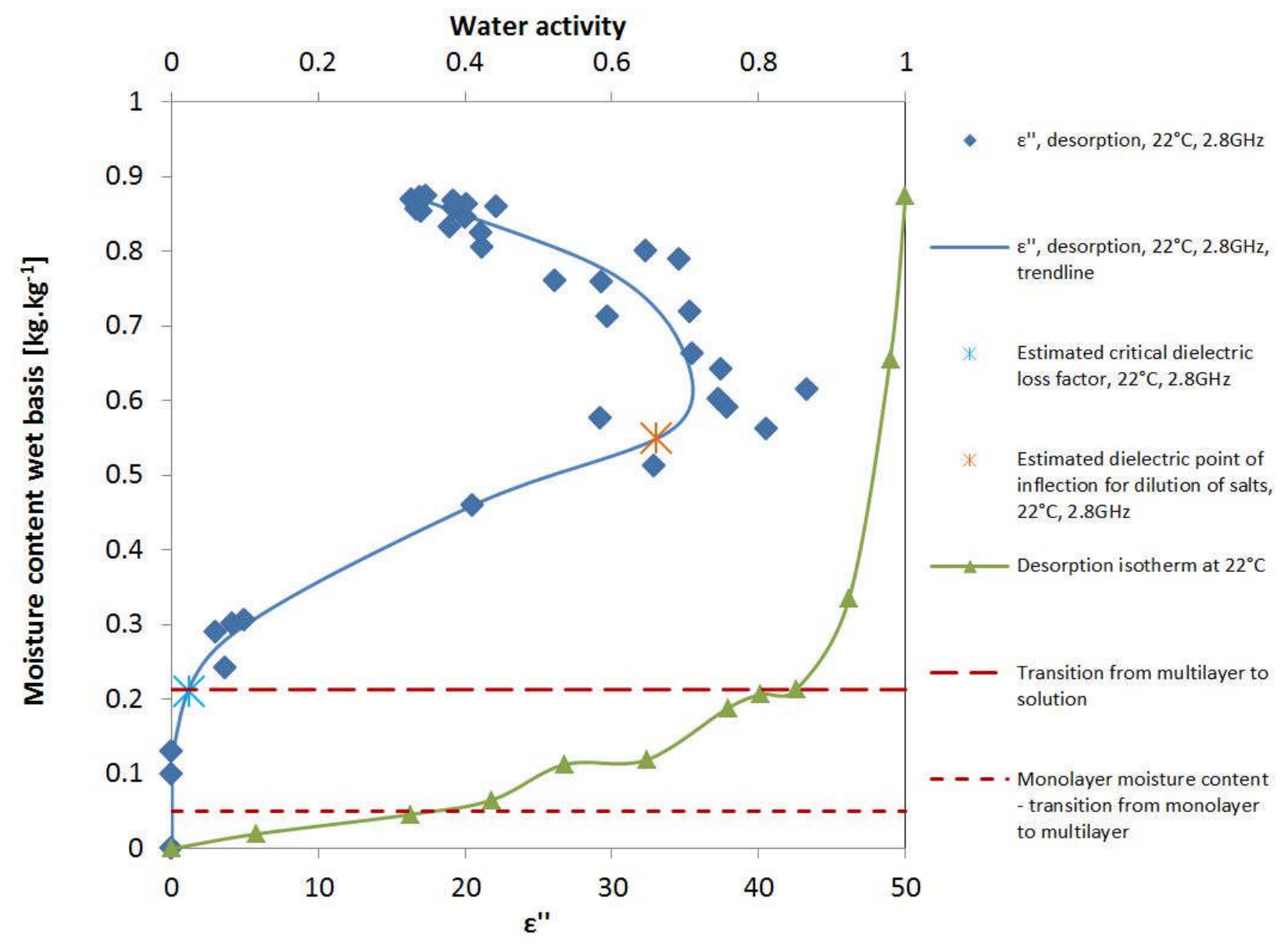

Fig. 2 - Desorption isotherm and corresponding loss factor at $22^{\circ} \mathrm{C}$ of potato at $2.8 \mathrm{GHz}$ taken from Holtz et al. (2010)

It can be seen that, similar to the Mudgett et al. (1980) data, there is no change in dielectric response at the monolayer. There is not enough data points to detect the jump in loss factor from 0.1 to 0.9 which occurred at $0.12 \mathrm{~kg}_{\mathrm{kg}} \mathrm{kg}^{-1}$ in the Mudgett et al. (1980) study. Also similar to the Mudgett et al. (1980) data, the point of inflection due to the transition to solution at $0.21 \mathrm{~kg} \cdot \mathrm{kg}^{-1}$ wet basis closely coincides with a large increase in $d \varepsilon " / d M_{w b}$. The point of inflection due to dilution of the salts is difficult to decipher in the Holtz et al. (2010) data due to the spread of data points. However, with the trendline used, it would appear that dilution of the salts begins to 
lower $d \varepsilon " / d M_{w b}$ at a moisture content of approximately $0.55 \mathrm{~kg}^{\mathrm{kg}} \mathrm{kg}^{-1}$ wet basis, which is higher than the Mudgett et al. (1980) value of $0.31 \mathrm{~kg} \cdot \mathrm{kg}^{-1}$. However, the zero point of $d \varepsilon " / d M_{w b}$ is approximately $0.6 \mathrm{~kg} \cdot \mathrm{kg}^{-1}$ wet basis, which is less subjective and agrees with the Mudgett et al. (1980) data. Both the data from Mudgett et al. (1980) and Holtz et al. (2010) shows that potato, being a starchy hydrocollid, has a large dielectric response relating to the transition from multilayer to solution, where water mobility is able to support microwave loss mechanisms. Any increase in $d \varepsilon^{\prime \prime} / d M_{w b}$ at the transition from monolayer to multilayer results is difficult to detect.

The moisture dependant loss factor and water activity of wheat flour is shown in Fig. 3 using best fit equations presented by Kim et al. (1998) and Moreira et al. (2010). The loss factor of wheat flour was measured by $\operatorname{Kim}$ et al. (1998) at $27 \mathrm{MHz}$, and looks very similar to the measurements of potato carried out by Mudgett et al. (1980) and Holtz et al. (2010) at $3 \mathrm{GHz}$ and $2.8 \mathrm{GHz}$ respectively. There is an initial change in $d \varepsilon " d M_{w b}$, which occurs just after the monolayer of $0.068 \mathrm{~kg} \cdot \mathrm{kg}^{-1}$ wet basis, then there is a very significant rise in $\mathrm{d} \varepsilon " / \mathrm{dM}_{\mathrm{wb}}$ at $0.27 \mathrm{~kg} . \mathrm{kg}^{-1}$ wet basis, followed by a decrease at $0.52 \mathrm{~kg} . \mathrm{kg}$ caused by dilution of the salts, with the rate of change turning negative at approximately $0.65 \mathrm{~kg} \cdot \mathrm{kg}^{-1}$ wet basis. The large increase in $d \varepsilon^{\prime \prime} / d M_{w b}$ at $0.27 \mathrm{~kg} \cdot \mathrm{kg}^{-1}$ wet basis is higher than the $0.19 \mathrm{~kg} \cdot \mathrm{kg}^{-1}$ wet basis point of inflection of water activity where the water starts to behave as a solution. This lag of loss factor response did not occur in the potato measurements presented by Mudgett et al. (1980) and Holtz et al. (2010). The lag in dielectric response could be due to the comparively low frequency of the measurement, however chickpea flour was measured by Guo et al. (2008) at both RF and microwave frequencies, and in each instance the critical dielcetric moisture content occurred at the ponit at which the water started to behave as a solution. Therefore, the lag in dielectric response for wheat flour may be due to other factors such as experimental error, or differences in food sample behaviour. The dielectric study was carried out by Kim et al. (1998) and the 
sorption study was carried out by Moreira et al. (2010), and they may have used a different type of wheat flour. This could result in a poorer coellation in results compared to data presented by Mudgett et al. (1980) and Holtz et al. (2010), each of which carried out both sorption and dielectric studies themselves, ensuring the food type was common between dielectric and sorption studies.

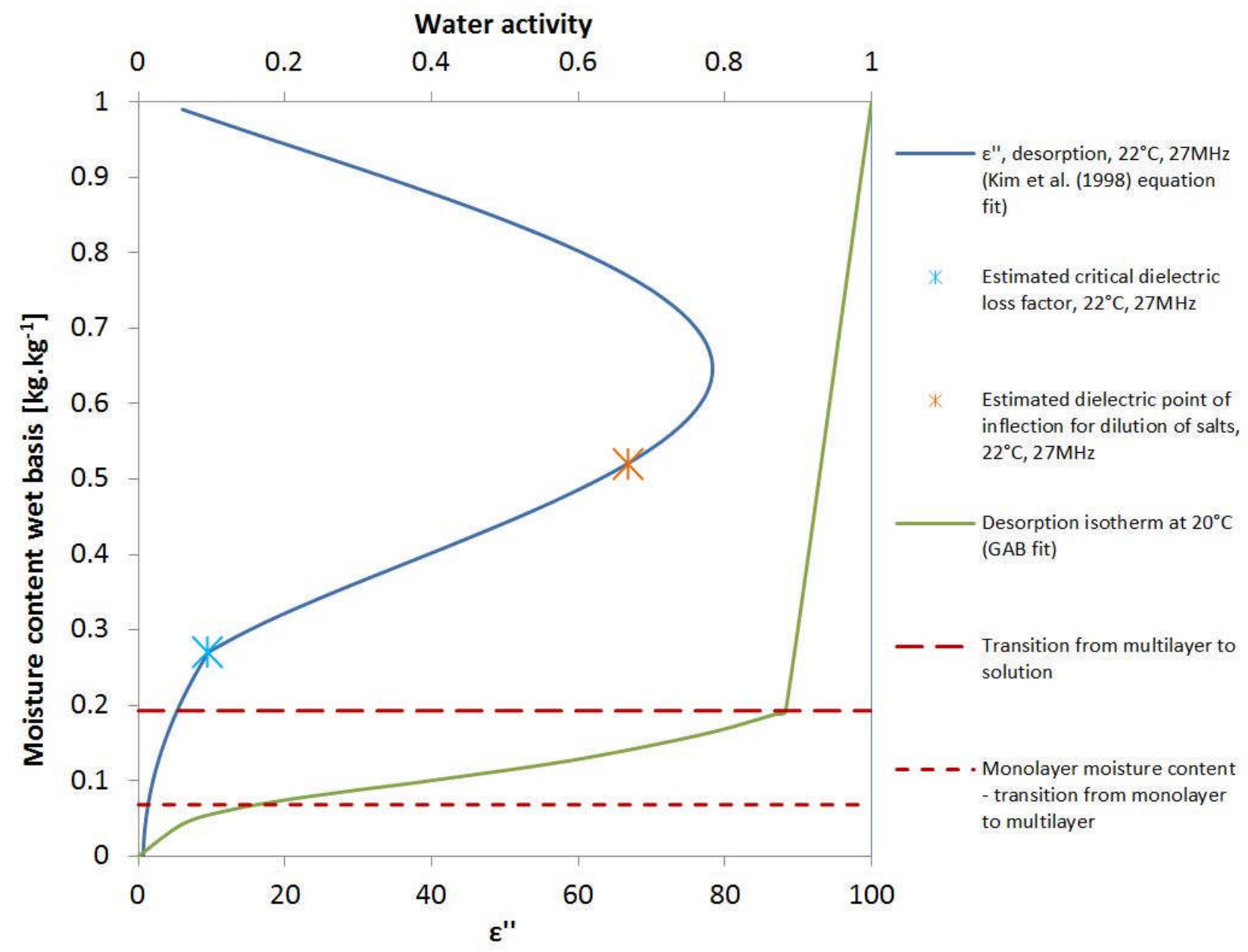

Fig. 3 - GAB fit Desorption isotherm at $20^{\circ} \mathrm{C}$ taken from Moreira et al. (2010) and loss factor at $22^{\circ} \mathrm{C}, 27 \mathrm{MHz}$ taken from wheat Kim et al. (1998) for wheat flour-water mixtures

The loss factor and water activity of chickpea flour is presented in Fig. 4, and Fig. 5 at temperatures of $20^{\circ} \mathrm{C}$ and $40^{\circ} \mathrm{C}$ respectively. Error bars are presented for both the dielectric properties and the sorption isotherms, representing the standard deviation of three replicates in each instance. Each figure contains plots of the loss factor at $27 \mathrm{MHz}$ and $1.8 \mathrm{GHz}$ compared to the sorption isotherm. A similar plot is shown for the desorption isotherm and loss factor of 
yellow dent corn in Fig. 6, where the loss factor was measured at $24^{\circ} \mathrm{C}, 20 \mathrm{MHz}$, and the desorption isotherm was measured at $25^{\circ} \mathrm{C}$. Error bars shown on the loss factor plot in Fig. 6 represent the standard deviation of 21 measurements, a best fit equation was used to present the sorption isotherm. Although none of these plots contain loss factor measurements at low moisture contents that encompasss the monolayer region, it is clear from the loss factor profile that there is only one large point of inflection at low moisture contents. In each instance this large point of inflection in the dielectric response corresponds very closely with the second point of inflection of the sorption isotherm, which is defined as the transition from multilayer to solution. Up to this point, the loss factor does not change significantly and is very low. $\mathrm{RF} / \mathrm{moisture}$ levelling requires a positive gradient of loss factor with respect to moisture content, and Fig. 4 to Fig. 6 shows that similar to potato and wheat flour, the loss factor does not vary much with respect to moisture content below the monolayer moisture content. More data points with suitable resolution are required to determine whether or not the loss factor has a positive gradient with respect to moisture content below the monolayer moisture content. Although the trends are similar for $27 \mathrm{MHz}$ compared to $1.8 \mathrm{GHz}$ for chickpea flour, the loss factor is higher at 27MHz. The higher loss factor observed at $27 \mathrm{MHz}$ is indicative of the presence of ionic conduction, as the contribution of ionic conduction to the loss factor is higher at lower frequencies (Tang, et al., 2002). Conversly the contribution of dipolar rotation to the dielectric loss is less at $27 \mathrm{MHz}$ compared compared to $1.8 \mathrm{GHz}$, as $27 \mathrm{MHz}$ is further away from the $17 \mathrm{GHz}$ relaxation frequency of water (Nelson \& Datta, 2001). Despite ionic conduction being the dominant loss mechanism at $27 \mathrm{MHz}$, and dipolar rotation being the dominant loss mechanism at $1.8 \mathrm{GHz}$, the point of inflection is the same. This potentially suggests that a very similar amount of water mobility is required for dipolar rotation and ionic conduction to occur in chickpea flour, and that both loss mechanisms occur when the moisture starts to behave as a solution. It is interesting to note that the loss factor point of inflection at $0.115 \mathrm{~kg}^{\mathrm{kg}} \mathrm{kg}^{-1}$ wet basis 
stays relatively constant when comparing the plots at $20^{\circ} \mathrm{C}, 30^{\circ} \mathrm{C}$, and $40^{\circ} \mathrm{C}$ for chickpea flour. However, both the transition from monolayer to multilayer and the transition from multilayer to solution decreases in terms of moisture content for a given water activity as temperature rises

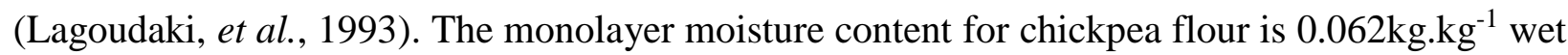
basis at $20^{\circ} \mathrm{C}, 0.053 \mathrm{~kg} \cdot \mathrm{kg}^{-1}$ wet basis at $30^{\circ} \mathrm{C}$, and $0.050 \mathrm{~kg} \cdot \mathrm{kg}^{-1}$ wet basis at $40^{\circ} \mathrm{C}$ as calculated using the BET model.

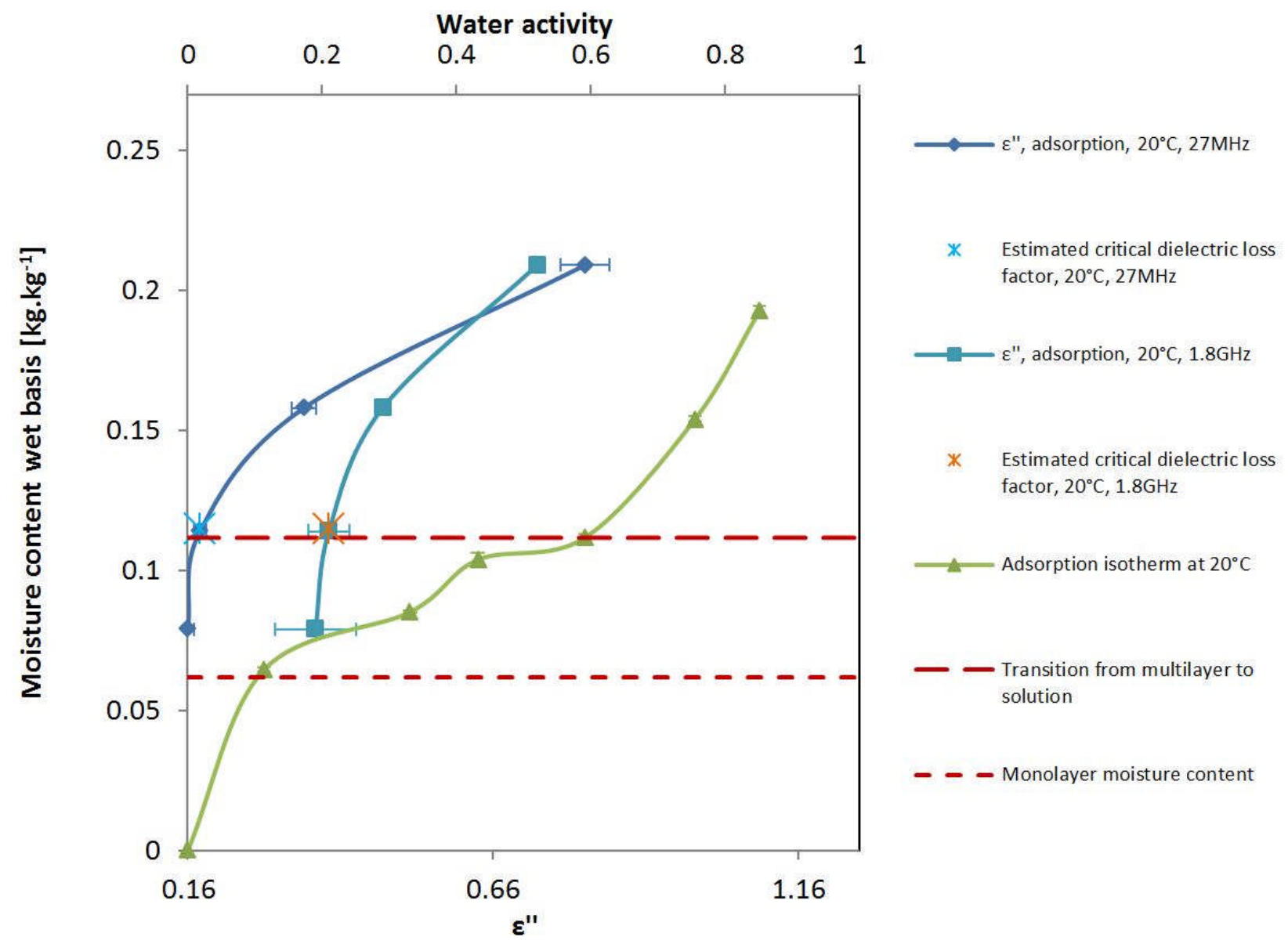

Fig. 4 - Chickpea flour adsorption isotherm at $20^{\circ} \mathrm{C}$ taken from Durakova \& Menkov (2005) and loss factor at $20^{\circ} \mathrm{C}$, at frequencies of $27 \mathrm{MHz}$ and $1.8 \mathrm{GHz}$, taken from Guo et al. (2008) of Chickpea flour

The loss factors plotted from Fig. 4 to Fig. 6 show no decrease in the rate of change of loss factor at higher moisture contents. However, this is not to say that dilution of ions does not occur, the point of inlfection associated with dilution of ions may occur at moisture contents that are higher than the moisture content range measured. 


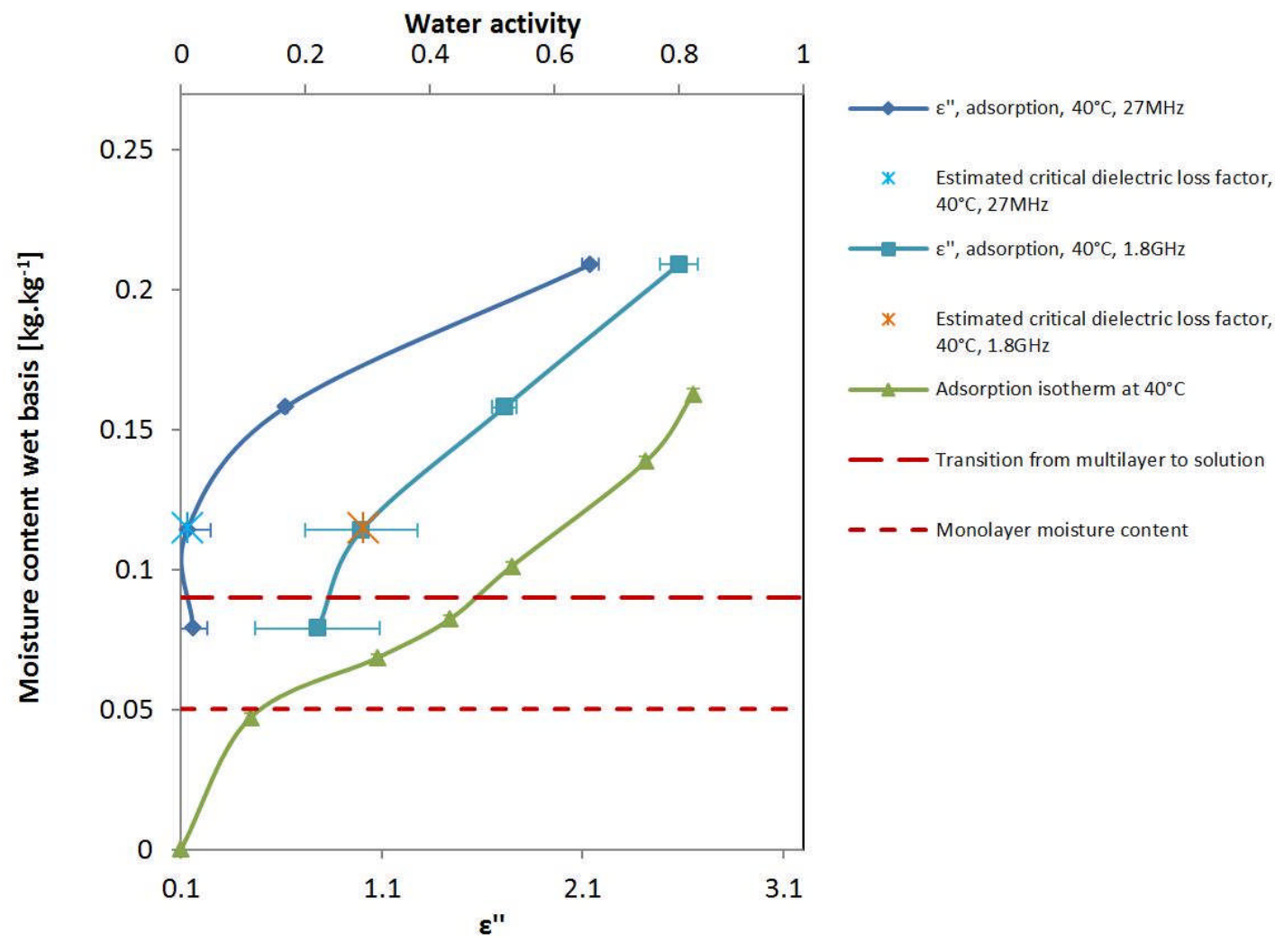

Fig. 5 - Chickpea flour adsorption isotherm at $40^{\circ} \mathrm{C}$ taken from Durakova \& Menkov (2005) and loss factor at $40^{\circ} \mathrm{C}$, at frequencies of $27 \mathrm{MHz}$ and $1.8 \mathrm{GHz}$, taken from Guo et al. (2008) of Chickpea flour

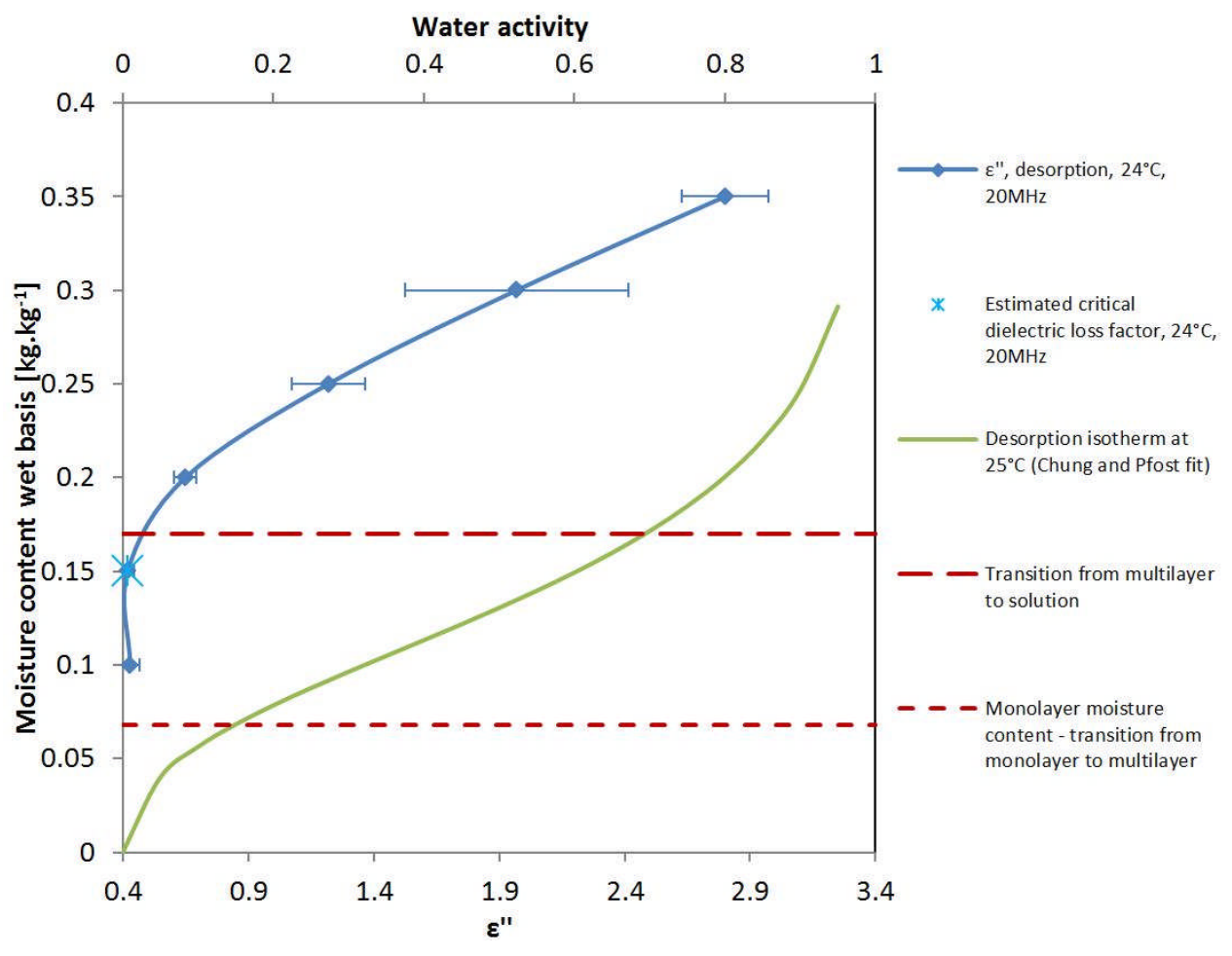

Fig. 6 - Chung and Pfost fit desorption isotherm at $25^{\circ} \mathrm{C}$ taken from Samapundo et al. (2007) and loss factor at $24^{\circ} \mathrm{C}, 20 \mathrm{MHz}$ taken from Nelson (1979) for yellow dent corn 
The sorption isotherm and corresponding loss factor for carboxymethyl cellulose (CMC) is shown in Fig. 7. The sorption isotherm is presented using a best fit equation, while the dielctric data is presented using points which are an average of triplicate measurements. Nelson et al. (1991) did not present the standard deviation or error bars associated with the triplicate measurements taken. Fig. 7 includes loss factor measurements below the monolayer moisture content. Similar to the previous plots, there is a point of inflection in the loss factor that directly corresponds to the point at which the moisture starts behaving as a solution. Hence, after the multilayer there is a large increase in loss factor. No reduction of $d \varepsilon " / d M_{w b}$ due to ionic dilution is observed, although this may occur at higher moisture contents which is beyond the range measured by Nelson et al. (1991).

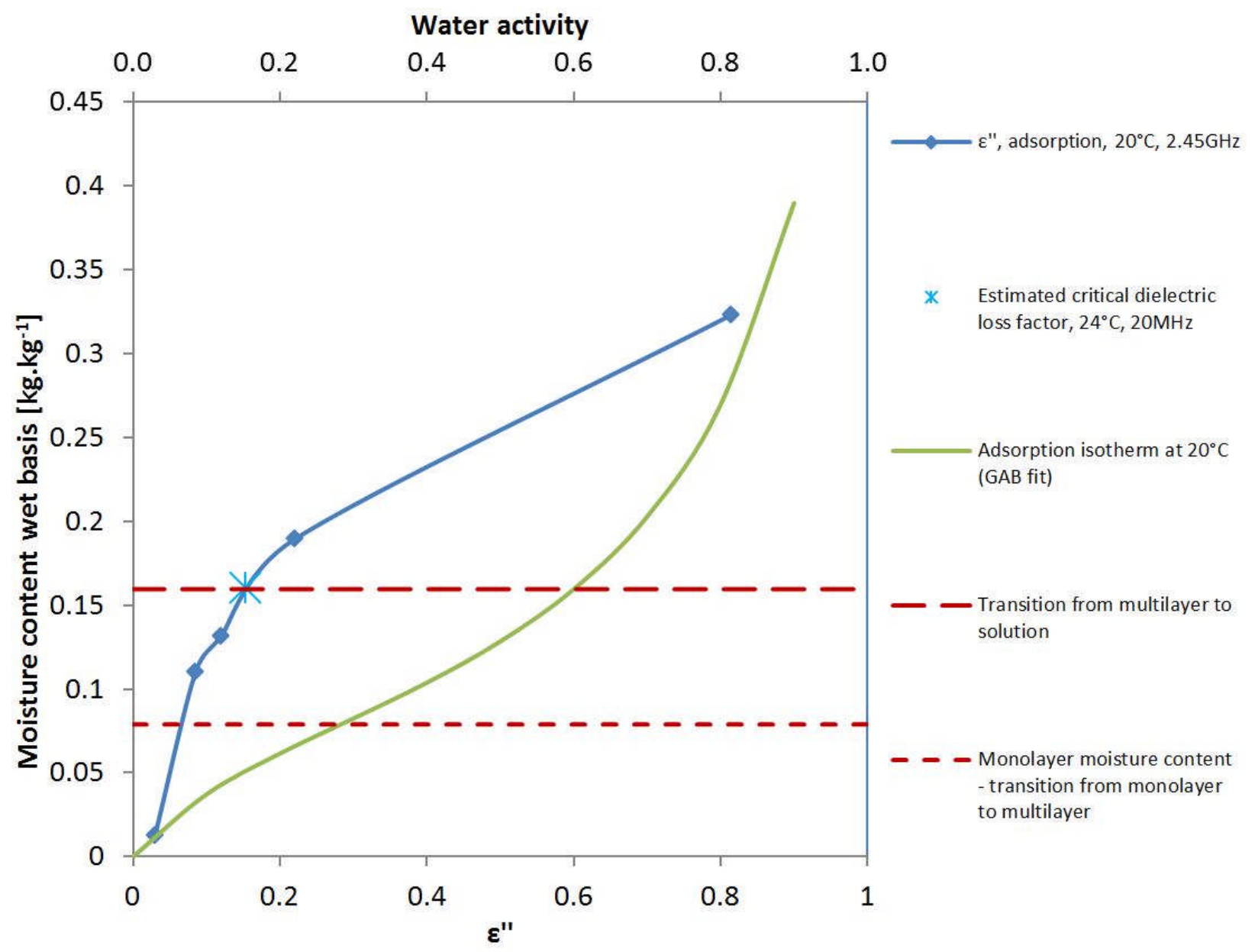

Fig. 7 - GAB fit adsorption isotherm at $20^{\circ} \mathrm{C}$ taken from Torres et al. (2012) and loss factor at $20^{\circ} \mathrm{C}, 2.45 \mathrm{GHz}$ taken from Nelson et al. (1991) for carboxymethyl cellulose 
It can be seen from Fig. 8 that the relationship between water activity and loss factor is different for apples than for potato, wheat flour, chickpea flour, yellow dent field corn, and carboxymethyl cellulose. It has been noted by Sipahioglu \& Barringer (2003) that vegetables have different dielectric behaviour than fruits. The sorption experiment was carried out with three replications to generate the average points presented in Fig. 8. Kaymak-Ertekin \& Gedik (2004) did not provide a standard deviation for each point, but instead stated that all standard deviation of replicates was within the range of $0.002-0.064 \mathrm{~kg} . \mathrm{kg}^{-1}$ dry basis. Three replicates were measured for the dielectric measurements, and the error bars represent the standard deviation in Fig. 8 .

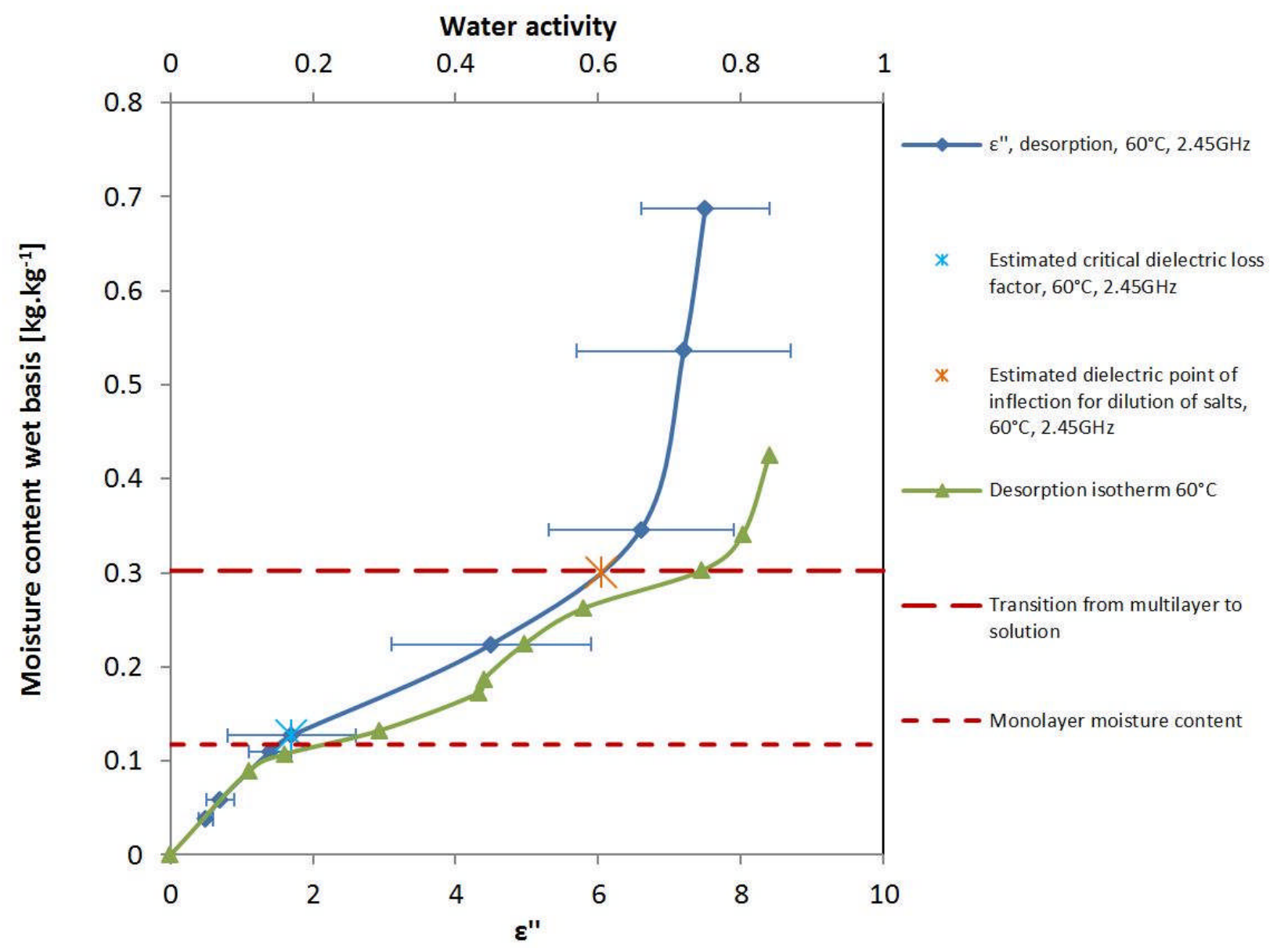

Fig. 8 - Desorption isotherm at $60^{\circ} \mathrm{C}$ taken from Kaymak-Ertekin \& Gedik (2004) and loss factor at $60^{\circ} \mathrm{C}$ taken from Martin-Esparza et al. (2006) of apples at $2.45 \mathrm{GHz}$

For apples, both the trend lines and the points of inflection are very closely aligned for loss factor and water activity. The rate of change of loss factor with respect to moisture content 
increases during the transition from monolayer to multilayer, and decreases during the transition from multilayer to solution. The decrease in $d \varepsilon " / d M_{w b}$ during the transition from multilayer to solution could be attributed to dilution of the salts, but it is more pronounced at $2.45 \mathrm{GHz}$ than at $915 \mathrm{MHz}$ despite the fact that ionic conduction would be more dominant at $915 \mathrm{MHz}$. If the decrease in $d \varepsilon^{\prime \prime} / d M_{w b}$ is due to dilution of salts, it would imply that salt dilution becomes significant in apples as soon as the water acts as a solution. The large increase in loss factor, which defines the critical dielectric moisture content, coincides with the monolayer moisture content. This is in contrast to potatoes and other vegetables assessed in the present study where a large increase in loss factor coincided with the transition from multilayer to solution. This contrast in dielectric behaviour would suggest that the multilayer of moisture is far more mobile and free to support dielectric loss mechanisms in apples which contain sugar, than the multilayer in potatoes and other low sugar foods with high hydrocolloid content. Hydrocolloids are long chain polysaccharide and protein polymers (Saha \& Bhattacharya, 2010). Starch is a polysaccharide commonly found in foods (Saha \& Bhattacharya, 2010; Ndife, et al., 1998). Presence of a large number of hydroxyl $(-\mathrm{OH})$ groups markedly increases their affinity for binding water molecules rendering them hydrophilic compounds (Saha \& Bhattacharya, 2010).

The desorption isotherm and loss factor for grapes at $30^{\circ} \mathrm{C}$ is shown in Fig. 9 at $25^{\circ} \mathrm{C}, 2.45 \mathrm{GHz}$. As with the sorption isotherm shown for apples in Fig. 8, three replicates were measured and the standard deviation of the measurements were within the range of $0.002-0.064 \mathrm{~kg}_{\mathrm{kg}} \mathrm{kg}^{-1}$ dry basis. The loss factor points presented are the average of four experiments, although standard deviation was not detailed by Tulasidas et al. (1995). The loss factor follows the trend of the sorption isotherm in the same way as was observed for apples in Fig. 8. This would suggest that fruits do behave differently from most low sugar foods that have high hydrocolloids content, where a large increase in loss factor occurs during the multilayer, and a decrease in the change of loss 
factor with respect to moisture content occurs when the moisture is in solution. In fruits such as grapes and apples the water predominantly interacts with sugar and pectin, whereas in vegetables such as potato, water predominantly interacts with starch carbohydrates and cellulose (KaymakErtekin \& Gedik, 2004; Maroulis, et al., 1988; McLaughlin \& Magee, 1998). The representative sugar (glucose + fructose + sucrose $)$ contents of grapes and apples are $0.44-0.45 \mathrm{~kg}_{\mathrm{kg}}{ }^{-1}$ wet basis and $0.43 \mathrm{~kg} \cdot \mathrm{kg}^{-1}$ wet basis respectively. Apples also have a pectin content of $0.065 \mathrm{~kg} \cdot \mathrm{kg}^{-1}$ wet basis. Potatoes are characterised by high starch content and contain $0.02 \mathrm{~kg}^{\mathrm{kg}} \mathrm{kg}^{-1}$ wet basis of sugars, and 0.44-0.46kg.kg ${ }^{-1}$ wet basis starch (Kaymak-Ertekin \& Gedik, 2004). The dielectric behaviour of grapes and apples would suggest that there is enough mobility to support dielectric loss mechanisms in the multilayer region, whereas low sugar foods with high hydrocolloids content can only support dielectric loss mechanisms strongly when the water acts as a solution. The loss factor is generally higher in fruit in the multilayer region compared to low sugar food with high hydrocolloid content, making it easier to couple microwave energy into the food for dehydrating down to the monolayer moisture content. There is a risk that the loss factor response is flat for part of the multilayer region in low sugar, hydrocolloid rich foods, with moisture not being selectively heated as a result. However, better resolution is required for dielectric measurements of low sugar foods with high hydrocolloid content in the low moisture content multilayer region to determine if the loss factor response is truly flat. Microwave heating below the monolayer content appears challenging for both fruits and vegetables as the loss factor is extremely low. Microwave finish drying of potato crisps at $915 \mathrm{MHz}$ is an example of a low loss material that proved difficult to process due to arcing/throughput. Schiffmann, (2001) reported that fires were not uncommon when finish drying potato crisps at at $896 / 915 \mathrm{MHz}$ due to the low dielectric loss of nearly dry potato crisps. This finish drying process dried potato crisps from 0.06-0.08kg. $\mathrm{kg}^{-1}$ wet basis down to less than $0.02 \mathrm{~kg} \cdot \mathrm{kg}^{-1}$ wet basis, and the drying equipment required fire detection and control systems. 


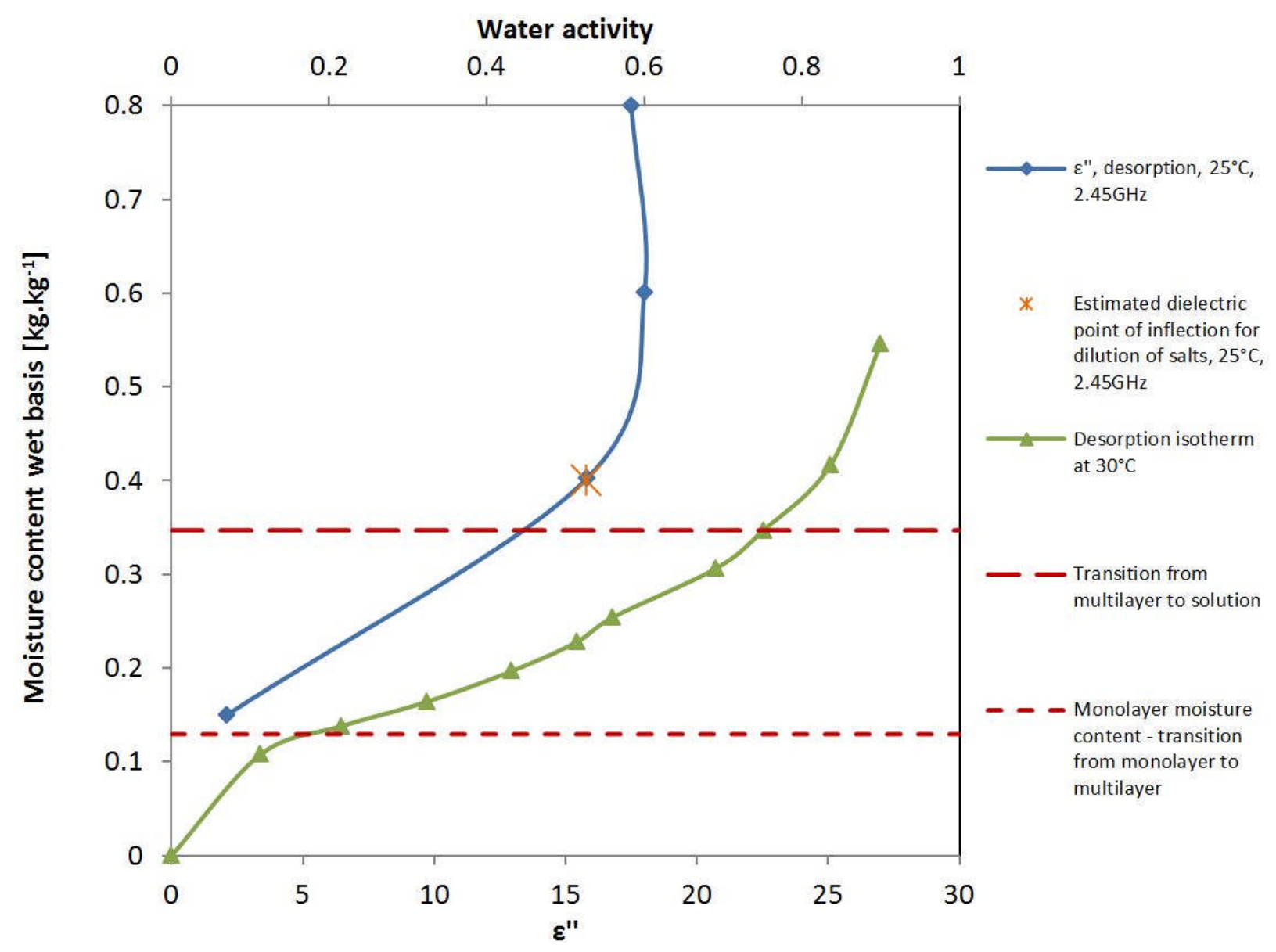

Fig. 9 - Desorption isotherm at $30^{\circ} \mathrm{C}$ taken from Kaymak-Ertekin \& Gedik (2004) and loss factor at $25^{\circ} \mathrm{C}$ taken from Tulasidas et al. (1995) of grapes at a frequency of $2.45 \mathrm{GHz}$

Table 2 shows the transition in states of the water as defined by the sorption isotherm compared to the points of inflection of loss factor. The sources used to obtain the data analysed in the present study is shown in Table 3. The critical dielectric moisture content and the corresponding transition in sorption is highlighted red in Table 2. It can be seen that the critical dielectric moisture content corresponds to the transition from multilayer to solution for all low sugar foods analysed that had high hydrocolloid content. It can be seen that for sugary fruits, the critical dielectric moisture content corresponds to the monolayer moisture content.

In every instance analysed, the transition from multilayer to solution corresponds to a point of inflection of loss factor with respect to moisture content, with an average difference of just 
$0.01 \mathrm{~kg} \cdot \mathrm{kg}^{-1}$ and a corresponding standard deviation of $0.03 \mathrm{~kg} \cdot \mathrm{kg}^{-1}$. The calculation of average difference in moisture content and corresponding standard deviation is shown in the right hand column in Table 2. The monolayer moisture content did not exhibit any significant response in dielectrics for most of the low sugar foods with high hydrocolloid content. The other significant observation is highlighted in green in Table 2, and this is that the transition from multilayer to solution corresponds with a decrease in the rate of change of loss factor with respect to increasing moisture content for sugary fruits. This decrease in the rate of change of loss factor is normally attributed to dilution of salts (Mudgett, et al., 1980). No such correlation can be made for non-sugary foods with high hydrocolloid content. Table 2 shows that in general, there was a distinct difference in behaviour observed in sugary fruits compared to low sugar foods with high hydrocolloid content. This can also be observed in the figures presented in this study. The large increase in $d \varepsilon " / d M_{w b}$ at the monolayer moisture content, and the large decrease in $d \varepsilon " / d M_{w b}$ at the transition from multilayer to solution observed in both apples and grapes (Figures 8 and 9) is not observed in the low sugar foods with high hydrocolloid content.

It can be seen in Table 2 that for all low sugar foods with high hydrocolloid content the dilution of salts only affects the loss factor at moisture contents that are at least $50 \%$ higher than the transition from multilayer to solution, if any reduction in loss factor due to dilution of salts is observed at all. For grapes and fruits a decrease in $d \varepsilon " / d M_{w b}$ is observed at the exact transition from multilayer to solution. This shows that sugary fruits tend to have a different dielectric behaviour from low sugar foods with high hydrocolloid content at high moisture contents. 


\section{Conclusions}

A correlation exists between the points of inflection observed for water activity with respect to moisture content, and for the points of inflection observed for loss factor with respect to moisture content. The monolayer-multilayer transition is not always apparent in loss factor response, however the transition from multilayer to solution provides a significant point of inflection for both water activity and loss factor that is highly correlated. The dielectric behaviour with respect to sorption isotherm points of inflection was found to be distinctly different for low sugar foods containing high levels of hydrocolloids compared to fruits.

The rate of change in loss factor with respect to moisture content remained relatively constant at the transition from monolayer to multilayer moisture for low sugar foods with high hydrocolloid content. A large increase in loss factor corresponding to the critical dielectric moisture content was found to occur at the transition from multilayer to solution at RF and microwave frequencies of $20 \mathrm{MHz}, 27 \mathrm{MHz}, 1.8 \mathrm{GHz}, 2.45 \mathrm{GHz}, 2.8 \mathrm{GHz}$, and $3 \mathrm{GHz}$. A decrease in $d \varepsilon " / d M_{w b}$ was observed at moisture contents at least $50 \%$ higher than the transition from multilayer to solution which is attributed to the dilution of salts. The decrease in loss factor due to salt dilution in food was found to occur at high frequencies of $3 \mathrm{GHz}$ as well as low RF frequencies of $27 \mathrm{MHz}$.

For sugary fruits, a large increase in loss factor corresponding to the critical dielectric moisture content was observed at the transition from monolayer to multilayer moisture. The large increase in loss factor observed during the monolayer-multilayer transition in fruits suggests that water in the multilayer is more able to support dielectric loss mechanisms in sugary fruits compared to low sugar foods with high hydrocolloid content. A decrease in $d \varepsilon " / d M_{w b}$ was found to occur in grapes and apples at the transition from multilayer to solution. 
This study shows that there would be a difference in microwave heating of fruits compared to low sugar foods with high hydrocolloid content when drying down to a specific water activity to achieve a desired shelf life. The implications of this difference in microwave heating behaviour with respect to water activity could be analysed in future studies. This study could also be expanded with further data and more foods/materials to better define the moisture dependant relationship between water activity and dielectric response.

\section{Acknowledgements}

The authors would like to thank e2v technologies for funding this research, and Stephen Spark, Adam Taylor and Steve Hurrell for making time available to complete this work.

\section{References}

Al-Muhtaseb, A. H., McMinn, W. A. M. \& Magee, T. R. A., 2002. Moisture sorption isotherm characteristics of food products: A review. Trans IChemE, Volume 80, pp. 118-128.

Bernussi, A. L. M., Chang, Y. K. \& Martinez-Bustos, F., 1998. Effects of production by microwave heating after conventional baking on moisture gradient and product quality of biscuits (cookies). Cereal chemistry, 75(5), pp. 606-611.

Bradshaw, S. M., Wyk, E. J. \& Swardt, J. B., 1998. Microwave heating principles and the application to the regeneration of granular activated carbon. The journal of the South African institute of mining and metallurgy, Issue July/August, pp. 201-210.

Brunauer, S., Emmett, P. H. \& Teller, E., 1938. Adsorption of gases in multimolecular layers. Journal of the American chemical society, Volume 60, pp. 309-319.

Clark, D. E. \& Sutton, W. H., 1996. Microwave processing of materials. Annual review of material science, Volume 26, pp. 299-331.

Durakova, A. G. \& Menkov, N. D., 2005. Moisture sorption characteristics of chickpea flour. Journal of food engineering, Volume 68, p. 535-539.

Feng, H., Tang, J. \& Cavalieri, R. P., 2002. Dielectric properties of dehydrated apples as affected by moisture and temperature. American Society of Agricultural Engineers, Volume 45, pp. 129135. 
Guo, W., Tiwari, G., Tang, J. \& Wang, S., 2008. Frequency, moisture and temperaturedependent dielectric properties of chickpea flour. Biosystems engineering, Volume 101, pp. 217224.

Gard, R. G., Poss, G. T. \& Barker, R., 2014. Microwave oven for roasting low moisture foods. USA, Patent No. US8759727 B2.

Holtz, E., Ahrné, L., Rittenauer, M. \& Rasmuson, A., 2010. Influence of dielectric and sorption properties on drying behaviour and energy efficiency during microwave convective drying of selected food and non-food inorganic materials. Journal of Food Engineering, Volume 97, p. $144-153$.

Jiao, S., Luan, D. \& Tang, J., 2015. Principles of radio-frequency and microwave heating. In: G. B. Awuah, H. S. Ramaswamy \& J. Tang, eds. Radio-frequency heating in food processing. CRC Press, Taylor: Boca Raton, pp. 3-20.

Kaymak-Ertekin, F. \& Gedik, A., 2004. Sorption isotherms and isosteric heat sorption for grapes, apricots, apples and potatoes. Swiss Society of food science and technology, Volume 37, pp. 429-438.

Kim, Y. R., Morgan, M. T., Okos, M. R. \& Stroshine, R. L., 1998. Measurement and prediction of dielectric properties of biscuit dough at $27 \mathrm{MHz}$. Journal of microwave power and electromagnetic energy, 33(3), pp. 184-194.

Koral, T., 2004. Radio frequency heating and post-baking. [Online] Available at: http://www.strayfield.co.uk/images/radio_frequency.pdf [Accessed 20 July 2016].

Labuza, T. P. \& Altunakar, B., 2007. Water Activity Prediction and Moisture Sorption Isotherms. In: G. V. Barbosa-Cánovas, J. A. J. Fontana, S. J. Schmidt \& T. P. Labuza, eds. Water activity in foods - Fundamentals and applications. Oxford: Blackwell publishing, pp. 109-110.

Lagoudaki, M., Demertzis, P. G. \& Kontominas, G., 1993. Moisture adsorption behaviour of pasta products. LWT - Food science and technology, 26(6), pp. 512-516.

Maroulis, Z. B., Tsarni, E. \& Marinos-Kouris, D., 1988. Application of the GAB model to the moisture sorption isotherms for dried fruits. Journal of food engineering, Volume 7, pp. 63-78.

Martin-Esparza, M. E., Martinez-Navarrete, N., Chiralt, A. \& Fito, P., 2006. Dielectric behaviour of apple (var. Granny Smith) at different moisture contents - Effect of vacuum impregnation. Journal of Food Engineering, Volume 77, pp. 51-56.

McLaughlin, C. P. \& Magee, T. R. A., 1998. The Determination of Sorption Isotherm and the Isoteric Heats of Sorption for Potatoes. Journal of Food Engineering, Volume 35, pp. 267-280.

McMinn, W. A. M., McKee, D. J. \& Magee, T. R. A., 2007. Moisture adsorption behaviour of oatmeal biscuit and oat flakes. Journal of food engineering, Volume 79, p. 481-493. 
Metaxas, A. C., 1996. Relaxation loss in dielectrics. In: Foundations of electroheat a unified approach. Chichester: Wiley, pp. 19-29.

Metaxas, A. C. \& Meredith, R. J., 1993. Dielectric properties. In: Industrial microwave heating. London: Peter Peregrinus, pp. 26-69.

Moreira, R., Chenlo, F., Torres, M. D. \& Prieto, D. M., 2010. Water adsorption and desorption isotherms of chestnut and wheat flours. Industrial Crops and Products, Volume 32, p. 252-257.

Mudgett, R. E., Goldblith, S. A., Wang, D. I. C. \& Westphal, W. B., 1980. Dielectric behaviour of a semi-solid food at low, intermediate and high moisture contents. Journal of Microwave Power, Volume 15, pp. 27-36.

Ndife, M. K., Şumnu, G. \& Bayindirli, L., 1998. Dielectric properties of six different species of starch at $2450 \mathrm{MHz}$. Food research international, Volume 31, pp. 43-52.

Nelson, S. O. \& Stetson, L. E., 1976. Frequency and moisture dependence of the dielectric properties of hard red winter wheat. Journal of agricultural engineering research, Volume 21, pp. 181-192.

Nelson, S. O., 1979. RF and microwave dielectric properties of shelled, yellow-dent field corn. Transactions of the American Society of Agricultural Engineers, 22(6), pp. 1451-1457.

Nelson, S. O. \& Datta, A. K., 2001. Dielectric properties of food materials and electric field interactions. In: A. K. Datta \& R. C. Anantheswaran, eds. Handbook of Microwave Technology for Food Applications. New York: Marcel Dekker, p. 4.

Nelson, S., Prakash, A. \& Lawrance, K., 1991. Moisture and temperature dependence of the permittivities of some hydrocolloids at $2.45 \mathrm{GHz}$. Journal of microwave power and electromagnetic energy, 26(3), pp. 178-185.

Richardson, J. F., Harker, J. H. \& Backhurst, J. R., 2002. Coulson \& Richardson's Chemical Engineering, Volume 2. 5th ed. Oxford: Elsevier, pp. 901-912.

Roberts, S. \& Von Hippel, A., 1946. A new method for measuring dielectric constant and loss in the range of centimeter waves. Journal of applied physics, Volume 17, pp. 610-616.

Sacilik, K. \& Colak, A., 2010. Determination of dielectric properties of corn seeds from 1 to 100 MHz. Powder technology, Volume 203, p. 365-370.

Saha, D. \& Bhattacharya, S., 2010. Hydrocolloids as thickening and gelling agents in food: a critical review. Journal of Food Science and Technology, 46(6), pp. 587-597.

Samapundo, S. et al., 2007. Sorption isotherms and isosteric heats of sorption of whole yellow dent corn. Journal of food engineering, Volume 79, p. 168-175.

Schiffmann, R. F., 2001. Microwave processes for the food industry. In: A. K. Datta, ed. Handbook of microwave technology for food applicatons. New York - Basel: Marcel Dekker, pp. 299-337. 
Schiffmann, R. F., 2006. Microwave and dielectric drying. In: A. S. Mujumdar, ed. Handbook of industrial drying third edition. Boca Raton: CRC Press, LLC, pp. 635-646.

Schmidt, S. J., 2007. Water mobility in foods. In: G. V. Barbosa-Cánovas, ed. Water activity in foods. Oxford: Blackwell publishing, p. 97.

Sipahioglu, O. \& Barringer, S. A., 2003. Dielectric properties of vegetables and fruits as a function of temperature, ash, and moisture content. Journal of food science, Volume 68, pp. 234239.

Sokhansanj, S. \& Jayas, D. S., 2006. Drying of foodstuffs. In: A. S. Mujumdar, ed. Handbook of industrial drying third edition. Boca Raton: CRC Press, LLC, pp. 522-545.

Tang, J., Hao, F. \& Lau, M., 2002. Microwave heating in food processing. In: X. H. Yang \& J. Tang, eds. Advances in Agricultural Science and Technology Volume 1: Advances in bioprocessing engineering. Singapore: World scientific publishing Co. Pte. Ltd., pp. pp1-43.

Toledo, R. T., 2007. Dehydration. In: Fundamentals of food process engineering. New York: Springer, pp. 431-473.

Torres, M. D., Moreira, R., Chenlo, F. \& Vázquez, M. J., 2012. Water adsorption isotherms of carboxymethyl cellulose, guar, locust bean, tragacanth and xanthan gums. Carbohydrate polymers, Volume 89, pp. 592-598.

Tulasidas, T. N., Raghavan, G. S. V., Van De Voort, F. \& Girard, R., 1995. Dielectric properties of grapes and sugar solutions at $2.45 \mathrm{GHz}$. Journal of microwave power and electromagnetic energy, 30(2), pp. 117-123.

Valipour, M., Banihabib, M. E. \& Behbahani, S. M. R., 2013. Comparison of the ARMA, ARIMA, and the autoregressive artifical neural network models in forecasting the monthly inlfow of Dez dam reservoir. Journal of hydrology, Volume 476, pp. 433-441.

Valipour, M., Sefidkouhi, M. A. G. \& Raeini-Sarjaz, M., 2017. Selecting the best model to estimate potential evapotranspiration with respect to climate change and magnitudes of extreme events. Agricultural water management, Volume 180, pp. 50-60.

Wang, N. \& Brennan, J. G., 1991. Moisture sorption isotherm characteristics of potatoes at four temperatures. Journal of food engineering, Volume 14, pp. 269-287 .

Yanniotis, S. \& Blahovec, J., 2009. Model analysis of sorption isotherms. LWT - Food Science and Technology, Volume 42, p. 1688-1695.

\begin{tabular}{|c|c|c|c|}
\hline Food & $\begin{array}{c}\text { Dielectric } \\
\text { measurement }\end{array}$ & Type of sorption & $\begin{array}{c}\text { Method of dielectric } \\
\text { measurement }\end{array}$ \\
\hline
\end{tabular}




\begin{tabular}{|c|c|c|c|}
\hline \multirow{2}{*}{ Potato } & $3 \mathrm{GHz}$ at $25^{\circ} \mathrm{C}$ & Adsorption & $\begin{array}{l}\text { Roberts \& Von Hippel (1946) } \\
\text { short circuited line technique }\end{array}$ \\
\hline & $2.8 \mathrm{GHz}$ at $22^{\circ} \mathrm{C}$ & Desorption & $\begin{array}{c}\text { Cavity perturbation (Holtz, et } \\
a l ., 2010)\end{array}$ \\
\hline Wheat flour & $27 \mathrm{MHz}$ at $22^{\circ} \mathrm{C}$ & Desorption & $\begin{array}{c}\text { Parallel plate capacitor (Kim, et } \\
\text { al., 1998) }\end{array}$ \\
\hline Chickpea flour & $\begin{array}{l}27 \mathrm{MHz} \text { at } 20^{\circ} \mathrm{C}, \\
30^{\circ} \mathrm{C} \text { and } 40^{\circ} \mathrm{C}, \\
1.8 \mathrm{GHz} \text { at } 20^{\circ} \mathrm{C}, \\
30^{\circ} \mathrm{C} \text { and } 40^{\circ} \mathrm{C}\end{array}$ & Adsorption & $\begin{array}{l}\text { Open-ended coaxial-line probe } \\
\quad(\text { Guo, et al., 2008) }\end{array}$ \\
\hline $\begin{array}{l}\text { Yellow dent field } \\
\text { corn }\end{array}$ & $20 \mathrm{MHz}$ at $24^{\circ} \mathrm{C}$ & Desorption & $\begin{array}{l}\text { A Boonton Q-meter, Type 160- } \\
\text { A, and the reactance variation } \\
\text { method (Nelson, 1979) }\end{array}$ \\
\hline $\begin{array}{l}\text { Carboxymethyl } \\
\text { cellulose }\end{array}$ & $2.45 \mathrm{GHz}$ at $20^{\circ} \mathrm{C}$ & Adsorption & $\begin{array}{l}\text { Roberts \& Von Hippel (1946) } \\
\text { short circuited line technique }\end{array}$ \\
\hline Apples & $\begin{array}{c}915 \mathrm{MHz} \text { and } \\
2.45 \mathrm{GHz} \text { at } 60^{\circ} \mathrm{C}\end{array}$ & Desorption & $\begin{array}{l}\text { Open-ended coaxial-line probe } \\
\text { (Martin-Esparza, et al., 2006) }\end{array}$ \\
\hline Grapes & $2.45 \mathrm{GHz}$ at $25^{\circ} \mathrm{C}$ & Desorption & $\begin{array}{l}\text { Open-ended coaxial-line probe } \\
\text { (Martin-Esparza, et al., 2006) }\end{array}$ \\
\hline
\end{tabular}

Table 1 - Foods with literature values for dielectrics and water activity that can be compared, with dielectric measurement technique and sorption type listed 


\begin{tabular}{|c|c|c|c|c|c|c|c|}
\hline Food & Temperature $\left[{ }^{\circ} \mathrm{C}\right]$ & Frequency & $\begin{array}{c}\text { Monolayer moisture } \\
\text { content }(w b) \text { from } \\
\text { sorption isotherm } \\
{\left[\mathrm{kg} \cdot \mathrm{kg}^{-1}\right]}\end{array}$ & $\begin{array}{l}\text { Transition from } \\
\text { multilayer to } \\
\text { solution moisture } \\
\text { content }(w b) \text { from } \\
\text { sorption isotherm } \\
{\left[\mathrm{kg} \cdot \mathrm{kg}^{-1}\right]}\end{array}$ & $\begin{array}{l}\text { Critical dielectric } \\
\text { moisture content } \\
(w b)\left[\mathrm{kg} \cdot \mathrm{kg}^{-1}\right]\end{array}$ & $\begin{array}{l}\text { Moisture content }(w b) \text { at } \\
\text { point of inflection of loss } \\
\text { factor corresponding to } \\
\text { dilution of salts }\left[\mathrm{kg} \cdot \mathrm{kg}^{-1}\right]\end{array}$ & $\begin{array}{l}\text { Moisture content (wb) } \\
\text { difference between sorption } \\
\text { isotherm transition from } \\
\text { multilayer to solution and } \\
\text { corresponding dielectric } \\
\text { point of inflection }\left[\mathrm{kg} \cdot \mathrm{kg}^{-1}\right]\end{array}$ \\
\hline $\begin{array}{c}\text { Freeze dried } \\
\text { potato }\end{array}$ & 25 & $3 \mathrm{GHz}$ & 0.076 & 0.2 & 0.16 & 0.31 & 0.04 \\
\hline Potato & 22 & $2.8 \mathrm{GHz}$ & 0.05 & 0.21 & 0.21 & 0.55 & 0 \\
\hline \multirow[t]{2}{*}{ Wheat flour } & $22\left(\right.$ for $\left.\varepsilon^{\prime \prime}\right), 20\left(\right.$ for $\left.a_{w}\right)$ & $27 \mathrm{MHz}$ & 0.068 & 0.19 & 0.27 & 0.52 & -0.08 \\
\hline & 20 & & 0.062 & 0.11 & & & -0.005 \\
\hline \multirow{2}{*}{$\begin{array}{c}\text { Chickpea } \\
\text { flour }\end{array}$} & 30 & $27 \mathrm{MHz}, 1.8 \mathrm{GHz}$ & 0.053 & 0.095 & 0.115 & No measurements & -0.02 \\
\hline & 40 & & 0.05 & 0.09 & & & -0.025 \\
\hline $\begin{array}{l}\text { Yellow dent } \\
\text { field corn }\end{array}$ & $24\left(\right.$ for $\left.\varepsilon^{\prime \prime}\right), 25\left(\right.$ for $\left.a_{w}\right)$ & $20 \mathrm{MHz}$ & 0.068 & 0.17 & 0.15 & No measurements & 0.02 \\
\hline $\mathrm{CMC}$ & $20 \mathrm{C}$ & $2.45 \mathrm{GHz}$ & 0.079 & 0.16 & 0.16 & No measurements & 0 \\
\hline Apples & 60 & $915 \mathrm{MHz}, 2.45 \mathrm{GHz}$ & 0.117 & 0.3 & 0.127 & 0.3 & 0 \\
\hline \multirow[t]{3}{*}{ Grapes } & $25\left(\right.$ for $\left.\varepsilon^{\prime \prime}\right), 30\left(\right.$ for $\left.a_{w}\right)$ & $2.45 \mathrm{GHz}$ & 0.13 & 0.35 & $<0.15$ & 0.4 & -0.05 \\
\hline & & & & & & Average difference $=$ & $-0.01 \mathrm{~kg} \cdot \mathrm{kg}^{-1}$ \\
\hline & & & & & & Standard deviation = & $0.03 \mathrm{~kg} \cdot \mathrm{kg}^{-1}$ \\
\hline
\end{tabular}

Table 2 - Critical dielectric moisture content and moisture content of point of inflection of loss factor corresponding to dilution of salts, compared to the transitional moisture contents of the state of the water as defined by the sorption isotherm 


\begin{tabular}{ccc}
\hline Food & Dielectric reference & Water activity reference \\
\hline Freeze dried potato & Mudgett, et al., 1980 & Mudgett, et al., 1980 \\
\hline Potato & Holtz, et al., 2010 & Holtz, et al., 2010 \\
\hline Wheat flour & Kim, et al., 1998 & Moreira, et al., 2010 \\
\hline Chickpea flour & Guo, et al., 2008 & Durakova \& Menkov, 2005 \\
\hline Yellow dent field corn & Nelson, 1979 & Samapundo, et al., 2007 \\
\hline Hydrocolloids & Nelson, et al., 1991 & Torres, et al., 2012 \\
\hline Apples & Feng, et al., 2002 & Kaymak-Ertekin \& Gedik, 2004 \\
\hline Grapes & Tulasidas, et al., 1995 & Kaymak-Ertekin \& Gedik, 2004 \\
\hline
\end{tabular}

Table 3 - References used to source sorption and dielectric data for the present study 